\title{
Türkiye'de COVID-19 Bulaşısının ARIMA Modeli ve LSTM Ă̆ı Kullanılarak Zaman Serisi Tahmini
}

\author{
Abdullah Ammar Karcıoğlu ${ }^{1 *}$, Sezercan Tanışman ${ }^{2}$, Hasan Bulut $^{3}$ \\ ${ }^{1 *}$ Ege Üniversitesi, Mühendislik Fakültesi, Bilgisayar Mühendisliği Bölümü, İzmir, Türkiye, (ORCID: 0000-0002-0907-751X), abdullah.ammar.karcioglu@ege.edu.tr \\ ${ }^{2}$ Ege Üniversitesi, Mühendislik Fakültesi, Bilgisayar Mühendisliği Bölümü, İzmir, Türkiye (ORCID: 0000-0002-8094-708X), sezercan.tanisman@ege.edu.tr \\ ${ }^{3}$ Ege Üniversitesi, Mühendislik Fakültesi, Bilgisayar Mühendisliği Bölümü, İzmir, Türkiye (ORCID: 0000-0002-4872-5698), hasan.bulut@ege.edu.tr
}

(International Conference on Design, Research and Development (RDCONF) 2021 - 15-18 December 2021)

(DOI: $10.31590 /$ ejosat.1039394)

ATIF/REFERENCE: Karcıŏlu, A. A., Tanışman, S., \& Bulut, H. (2021). Türkiye'de COVID-19 Bulaşısının ARIMA Modeli ve LSTM Ağ1 Kullanılarak Zaman Serisi Tahmini. Avrupa Bilim ve Teknoloji Dergisi, (32), 288-297.

\section{$\ddot{O} z$}

11 Mart 2020'de Dünya Sağlık Örgütü (WHO), 2019 yılı yeni tip korona virüsünü küresel salgın olarak ilan etmiştir. COVID-19 olarak da bilinen yeni tip korona virüsü, ilk olarak Aralık 2019'da Çin'in Wuhan şehrinde ortaya çıkmış ve birkaç hafta içinde tüm dünyaya yayılmıştır. Tüm dünyada 5 milyondan fazla insan, Türkiye’de ise 70 bine yakın insan bu hastalıktan dolayı vefat etmiştir. Küresel çapta insan sağlığını tehtit eden ve ekonomik krizlere neden olan bu salgınla mücadelede önceden önlem almak hayati önem taşımaktadır. COVID-19 salgının yayılmasının tahmin edilmesi bu hastalıkla ilgili ne gibi önlemler alınacağı hakkında fikir verir. Bu çalışmada, ARIMA zaman serisi modeli ve LSTM ağı kullanılarak Türkiye'deki COVID-19 salgınında günlük vaka saysı, günlük iyileşen sayısı ve günlük vefat sayısı tahmini gerçekleştirilmiştir. Modellerin doğruluğunu test etmek için bilinen ve bilinmeyen verilerin tahmini yapılarak, tahmini yapılan verilerin hata yüzdeleri karşılaştırılmıştır. Türkiye'de COVID-19 bulaşı seyrinin gelecek 15 günlük tahmini için yapılan deneysel çalışmalar sonucu günlük vaka sayılarında ve günlük vefat sayılarında ARIMA modeliyle yüksek doğrulukta tahminleme yapılırken, günlük iyileşen sayılarında ise LSTM modeliyle yüksek doğrulukta tahminleme yapıldığı gözlemlenmiştir. ARIMA ve LSTM modellerinde günlük vaka ve vefat sayılarında azalma seyri gözlemlenmiştir. Ancak günlük iyileşme sayılarında ARIMA modelinde azalma, LSTM modelinde artış gözlemlenmiştir.

Anahtar Kelimeler: Zaman Serisi Tahmini, Makine Öğrenmesi, COVID-19.

\section{Time Series Forecasting of COVID-19 Transmission in Turkey Using ARIMA Model and LSTM Network}

\begin{abstract}
On March 11, 2020, the World Health Organization (WHO) declared the new coronavirus 2019 as a global epidemic. The new type of coronavirus, also known as COVID-19, first appeared in Wuhan city of China in December 2019 and spread all over the world within a few weeks. More than 5 million people all over the world and nearly 70,000 people in Turkey have died due to this disease. It is vital to take precautionary measures in the fight against this epidemic, which threatens human health on a globally and causes economic crises. The forecasting of the spread of the COVID-19 epidemic gives an idea about what measures to take regarding this disease. In this study, daily number of cases, daily number of recoveries and daily number of deaths were estimated in the COVID-19 outbreak in Turkey using the ARIMA time series model and LSTM network. To test the accuracy of the models, known and unknown data were estimated and the error percentages of the estimated data were compared. As a result of the experimental studies carried out to predict the course of COVID-19 transmission in Turkey for the next 15-days, it has been observed that the daily number of cases and daily number of death sare estimated with high accuracy in the ARIMA model, while the daily number of recoveries are estimated with high accuracy in the LSTM model. In the ARIMA and LSTM models, a decrease was observed in the number of daily cases and deaths. However, a decrease in the daily number of recoveries in the ARIMA model and an increase in the LSTM model were observed.
\end{abstract}

Keywords: Time Series Forecasting, Machine Learning, COVID-19.

\footnotetext{
*Sorumlu Yazar: abdullah.ammar.karcioglu@ege.edu.tr
} 


\section{Giriş}

COVID-19, 11 Mart 2020 tarihinden bu yana Dünya Sağlık Örgütü (WHO) tarafından küresel salgın ilan edildiğinden beri, şiddetli akut solunum sendorumu salgına dönüşerek dünya çapında etkisi büyük bir pandemi haline gelmiştir. Küresel çapta ülkeleri olumsuz yönde etkileyen bu pandemi, ekonomik krizlere, işsizliğe, eğitim-öğretim programlarının aksamasına neden olmuştur [1]. Dünyada birçok sektörde olumsuzluklara neden olan COVID-19 salgını, hükümet ve araştırmacıların, akademik kurumların ve endüstri kuruluşlarının, salgını önlemeye yönelik olarak ortak hedefler etrafinda birleşmesine neden olmuştur. Sağlık hizmetlerinin kaynaklarının planlanması, salgını önlemek için aşı geliştirme çalışmalarının başlatılması, gündelik hayatı normalleştirecek adımların atılması, yeni eğitim yöntemlerinin geliştirilemesi gibi salgınla alakalı birçok çıktının elde edilmesini sağlamıştır.[2].

Türkiye'de 10 Mart 2020'de ilk COVID-19 hastasıyla vakalar bildirilmeye başlanmıştır. Virüsün yayılma şiddeti ortaya çıkınca, pandemiyi kontrol altına almak için Türkiye hükümeti tarafından kısmi sokağa çıkma yasağı uygulanmıştır. İlk izolasyon duyurulmuş ve kademeli olarak 10 Nisan'dan Haziran'a kadar uzatılmıştır [3].29 Nisan- 17 Mayıs 2021 tarihleri arası iki haftalık sokağa çıkma yasağı ilan edilmiştir. Yapılan bu karantina önlemlerinde vaka sayılarında ciddi bir düşüş elde edilmiştir. 1 Temmuz itibariyle de yurt genelinde yasaklar kaldırılmış ve vaka sayılarında artış gözlemlenmiştir. Hükümet tarafından birçok maske, mesafe ve sokağa çıkma gibi önlemler alınmasına rağmen artan vaka sayılarının tahmin edilebilir olması, sağlık altyapısının daha verimli kullanılmasını ve ekonomik istikrarı yeniden sağlama yönünde olumlu izlenimler kazandıracaktır.

Hükümetler çok sayıda kısıtlama ve sosyal mesafe önlemi uygulasa da sağlık sistemlerine olan ihtiyaç önemli ölçüde artmıştır ve enfekte hastaların etkin yönetimi hastaneler için bir sorun haline gelmiştir. Bu nedenle, mevcut kaynakları optimize etmek ve hastalıkların ilerlemesini durdurmak veya yavaşlatmak için vaka sayılarının kısa vadeli tahmini önem arzetmektedir [4]. Ülke genelinde meydana gelen hastalığın yayılma hızı, sayısı ve yönü önceden tahmin edilebilirse hükümetlerin alacağı kararlar, sağlık hizmetlerininin hastalığı önlemede uygulayacağı algoritmalar öngörülebilir. Böylelikle, hastalığa karşı zaman serisi modellerine dayalı algoritmaları kullanarak önceden elde ettiğimiz tahminler sayesinde sağlık hizmetlerinde uygulanacak programların daha etkili oluşturulması sağlanacaktır.

$\mathrm{Bu}$ çalışmada, Türkiye'de meydana gelen COVID-19 salgınında günlük vaka sayısı, günlük iyileşen sayısı ve günlük vefat sayıs1 ARIMA zaman serisi modeli ve LSTM sinir ağı kullanılarak salgının zaman serisi tahmini gerçekleştirilmiştir. Yapılan çalışmada 15 günlük gelecek tahmini yapılarak farklı modellerle elde edilen sonuçlar karşılaştırılmıştır. Çalışmanın geri kalanı şu şekilde yapılandırılmıştır: İkinci bölümde, ilgili çalışmalar tanıtılmaktadır. Çalışmanın üçüncü bölümünde, materyal ve yöntemler, dördüncü bölümde deneysel sonuçlar, son bölümde ise çalışmanın genel sonuçlarına ve gelecekte yapılabilecek çalışmalara değinilmektedir.

\section{2. İlgili Çalışmalar}

Zaman serisi tahmini önceden elde edilen bilgilerden yola çıkarak gelecek hakkında incelenen olayın zaman içindeki seyrinin tahmin edilmesine dayanmaktadır. Literatürde zaman serisi modellerinden ARIMA modeli ve derin öğrenme modellerinden uzun kısa süreli bellek hafızasını kullanarak zaman serisi tahmini gerçekleştiren LSTM ağları birçok alanda tahminleme yapmak üzere kullanılmıştır. COVID-19 vakalarının zaman serileri analizine yönelik olarak gerçekleştirilmiş birçok bilimsel çalışma bulunmakla birlikte, bu bölümün geri kalanında ilgili alandaki temel çalışmalara değinilmektedir.

Baramn [5], ARIMA modelini ve birkaç LSTM mimarisini kullanarak 4 ülkedeki (ABD, İtalya, İspanya ve Almanya) COVID-19 vaka sayılarının zaman serisi analizini ve tahminini sunmuştur. Anne [6], katlanarak büyüyen COVID-19 salgınının zaman serisinin aktarımının kısa vadeli tahminini yapmak için ARIMA modelini kullanmıştır ve bir zaman aralığındaki toplam vaka sayısı üzerinde bunu gerçekleştirmiştir. Ding vd. [7] İtalya'da 24 Şubat-30 Mart 2020 arasındaki salgın verilerini istatistiksel olarak analiz etmiştir ve ARIMA modeline dayalı basit bir zaman serisi analiz modelini önermişlerdir. Shai vd. [8] salgının yayılmasını tahmin etmek için COVID-19'dan etkilenen ilk beş ülkenin ARIMA zaman serisi modeline dayalı zaman serisi analizini gerçekleştirmişlerdir. Maleki vd. [9] önerdikleri zaman serisi modellerini kullanarak COVID-19'un dünyadaki yayılma ve ölüm oranını tahmin etmişlerdir. Papastefanopoulos vd. [10], 4 Mayıs 2020 itibarıyla en fazla teyit edilmiş vaka sayısına sahip on farklı ülkede koronavirüs salgını tespiti için çeşitli zaman serisi modelleme yaklaşımlarının doğruluğunu araştırmışlardır. Chimmula vd. [11] Kanada ve dünyadaki COVID-19 salgınının eğilimlerini ve olası durma süresini tahmin etmek için temel özellikleri değerlendirmişlerdir ve gelecekteki COVID-19 vaka tahmini için derin öğrenme yaklaşımı olan LSTM ağlarını sunmuşlardır. Maleki vd. [12] doğrulanan ve iyileşen COVID-19 vakalarını tahmin etmek için iki parça ölçekli normal dağılıma sahip zaman serisi modellemesine dayalı otoregresif modelleri önermişlerdir.

Türkiye'deki COVID-19 vakalarının zaman serisi modelleri kullanılarak tahmin edilmesine yönelik literatürde birçok çalışma gerçekleştirilmiştir. Akay ve Akay [13] 11 Mart 2020'den 24 Ağustos 2020'ye kadar olan toplam vaka sayısını tahmin etmek için ARIMA modelini kullanmışlardır. Tahmin gerçekleştirmek için 25 Ağustos 2020'den 7 Eylül 2020'ye kadar ki 14 günlük vakaların tahmini ve analizi yapılmıştır. Ankaralı [14] zaman serisi modellerini kullanarak Türkiye'de COVID-19 salgın sürecinde ihtiyaç duyulacak yoğun bakım yatak ve solunum cihazı sayılarının direkt tahminini gerçekleştirmiştir. Koçak [15] Türkiye'deki COVID-19 vaka sayılarının tahmini için farklı zaman serisi modellerini kullanarak analiz sonuçlarını karşılaştırmıştır. Ergül vd. [16] büyüme eğrilerini ve zaman serisi analizlerini kullanarak Türkiye'deki vaka sayılarının tahminini gerçekleştirmişlerdir. Bayar ve Varışlı [17] en küçük kareler yöntemi ve zaman serisi yöntemlerini kullanarak Türkiye'deki COVID-19 salgının tüketici kredileri hacmi üzerindeki etkisinin tahminini gerçekleştirmişlerdir. Demir [18] bir sekteli zaman serisi analizini kullanarak Türkiye'deki salgının seyrini ve bu salgının ekonomiye olan etkilerini tahmin etmiştir. Karasu ve Doğu [19] Johns Hopkins Üniversitesi resmî web sitesinde gerçek zamanlı derlenen verileri kullanarak Türkiye'deki COVID-19 salgının gerçek zamanlı seyrine olanak sağlayan bir web arayüz tasarlamışlardır. Er vd. [20] Türkiye'nin de içinde olduğu birçok ülkedeki COVID-19 vakalarının tahminini gerçekleştirmek için frekans güncellemesine dayalı ARIMA modelini kullanmışlardır. Ergül vd. [21] dünyada ve Türkiye'de nisan ayı itibariyle COVID19 salgın verilerinin istatistiksel değerlendirilmesi için ARIMA zaman serisi modelini kullanmışlardır. 


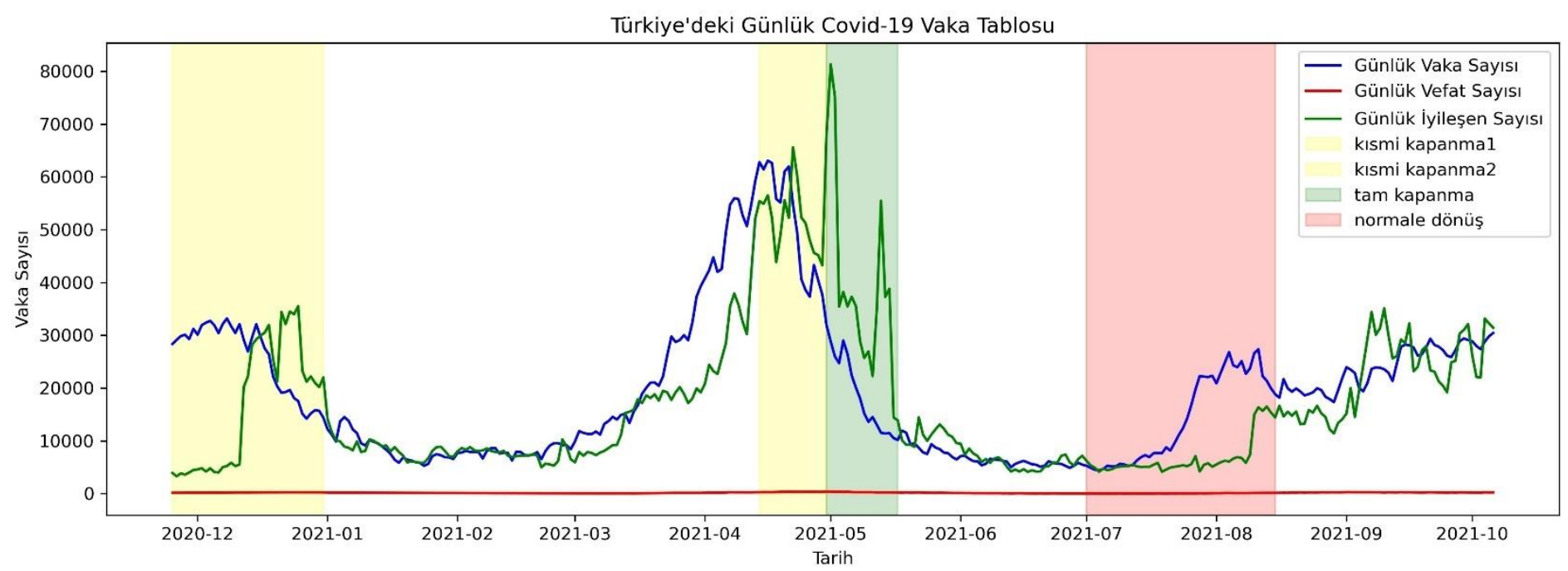

Şekil 1. Türkiye'deki Günlük COVID-19 Grafiği

\section{Materyal ve Yöntemler}

\subsection{Kullanılan Veri Seti}

Çalışma kapsamında kullanılan veri seti Türkiye'deki günlük COVID-19 bulaşısının zaman serisi modelleri ile tahmin etmek için sağlık bakanlığının halka açık şekilde duyurduğu https:/covid19.saglik.gov.tr/TR-66935/genel-koronavirustablosu.html internet sayfasından elde edilmiştir ve Şekil 1'de gösterilmiştir. 25 Kasım 2020 - 6 Ekim 2021 tarihleri arasındaki Türkiye'de meydana gelen günlük vaka sayısı, günlük vefat sayısı ve günlük iyileşen sayısı Şekil 2'de gösterildiği gibi veri seti olarak toplanmıştır. Başlangıç tarihi olarak 25 Kasım 2020 alınmasının nedeni, sağlık bakanlığının günlük vaka sayılarını bu tarihten itibaren açıklamaya başlamasıdır.

\begin{tabular}{rrrrr} 
& Tarih & BugunkuVakasayisi & BugunkuVefatSayisi & Bugunkulyilesen Sayisi \\
\hline 0 & $2020-11-25$ & 28351 & 168 & 3911 \\
1 & $2020-11-26$ & 29132 & 174 & 3291 \\
2 & $2020-11-27$ & 29845 & 177 & 3845 \\
3 & $2020-11-28$ & 30103 & 182 & 3611 \\
4 & $2020-11-29$ & 29281 & 185 & 4015 \\
$\ldots$ & $\ldots$ & $\ldots$ & $\ldots$ & $\ldots$ \\
311 & $2021-10-02$ & 27973 & 203 & 22110 \\
312 & $2021-10-03$ & 27351 & 194 & 22004 \\
313 & $2021-10-04$ & 28810 & 248 & 33152 \\
314 & $2021-10-05$ & 29802 & 228 & 32269 \\
315 & $2021-10-06$ & 30438 & 236 & 31413
\end{tabular}

Şekil 2. Veri Seti

\subsection{Zaman Serisi Tahmin Modelleri}

\subsubsection{ARIMA Zaman Serisi Modeli}

Otoregresif hareketli ortalama modeli $\operatorname{ARIMA}(p, d, q)$ bir zaman serisi analizi ve tahmin yöntemidir. Zaman serisinin durağan olmadığı durumlarda kullanılır. ARIMA modelinin üç bileşeni vardır:

- Otoregresyon (AR): Otoregresif bir model, kendi önceki (veya gecikmeli) değerlerine dayalı olarak değişen bir değişken arasındaki regresyon ilişkisini türetir.

- Entegrasyon (I): Entegrasyon, ham gözlemler arasındaki farkları modellemeyi ifade eder, böylece zaman serileri durağan kabul edilebilir. Başka bir deyişle, ham değerler, ham değerler ile önceki değerler arasındaki farklarla değiştirilir.

- Hareketli Ortalama (MA): Modeldeki hareketli ortalama bileşeni, bir gözlem ile önceki (veya gecikmeli) gözlemlere uygulanan hareketli ortalama modelinden kalan bir hata arasındaki ilişkiyi içerir. ARIMA modeli 3 parametreye sahiptir.

1. $p$, otoregresif (AR) modelin derecesini temsil eder.

2. $d$, serinin durağanlaştırılabilmesi için kaçıncı dereceden farkının alındığını temsil eder.

3. $q$, hareketli ortalama penceresinin boyutunu gösterir.

ARIMA modelinin $(1,0,0)$ modeli bu çalışmada kullanılmıştır ve tahmin edilecek gün sayısı $t=15$ gün olarak belirlenmiştir. Birinci mertebeden otoregresif model olan ARIMA $(1,0,0$, modeli, seri durağan ise ve otokorelasyonlu ise, kendi önceki değerinin bir katı artı bir sabit olarak tahmin edilebilir. ARIMA modelinde gelecekteki doğrulanmış COVID-19 vakalarını tahmin etme modeli Denklem 1'de gösterilmiştir.

$\operatorname{ARIMA}(\mathrm{p}, \mathrm{d}, \mathrm{q}): X_{t}=\alpha_{1} X_{t-1}+\alpha_{2} X_{t-2}+\beta_{1} Z_{t-1}+\beta_{2} Z_{t-2}+$

$Z_{t} \quad$ ve $Z_{t}=X_{t}-X_{t-1}$

Burada $X_{t}, t$. günde tahmini doğrulanmış COVID-19 vakası sayısıdır, $\alpha_{1}, \alpha_{2}, \beta_{1}$ ve $\beta_{1}$ parametrelerdir, $Z_{t}$ ise $t$. gün için kalan terimdir. Çalışmada kullanılan ARIMA zaman serisi modelinin genel çerçevesi Şekil 3 'te gösterilmiştir.

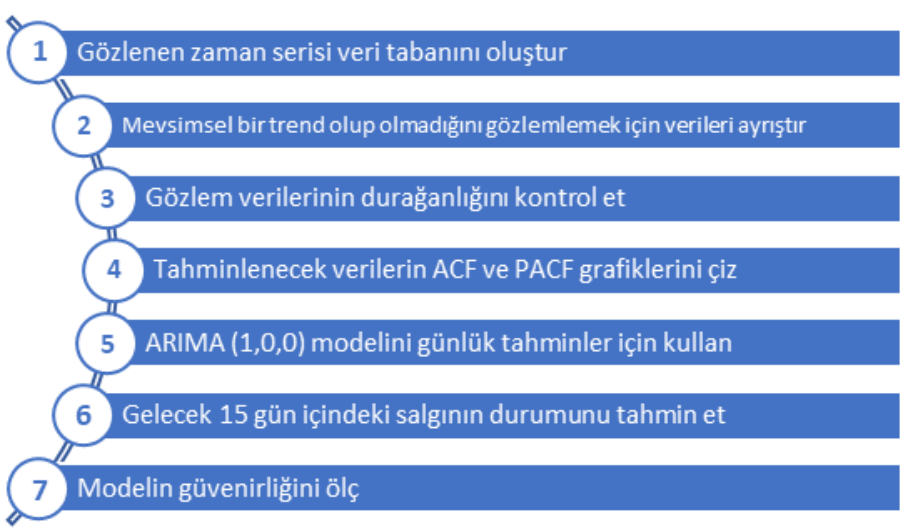

Şekil 3. ARIMA Modeli Genel Çerçevesi 


\subsubsection{LSTM Sinir A $\check{g} \mathrm{l}$}

LSTM sinir ağı, bir önceki adımın çıktısını mevcut adımın girdisi olarak kullanan ve kısa bir süre belleğinde tutan RNN ağları ile çok benzer olan ancak RNN ağlarının karşılaştı̆̆ sorunları çözmek için geliştirilmiş yapay sinir ağıdır. Böylelikle, doğal dil işleme ve zaman serileri gibi problemlerin çözülmesinde kullanılabilirler. RNN ağları bilgiyi uzun süreli tutmakta başarısız olduğu için önemli bazı bilgiler ağın başında kaybolabilir. Aynı zamanda RNN ağları, geri yayılım süresince gradyan yok olması gibi problemlere sahiptir. Genel işleyişi Şekil 4'te gösterilen LSTM ağ 1 bahsedilen bu kısıtlamalara karşı geliştirilmiş bir modeldir. LSTM hücreleri kısa süreli bellek sorununu çözmek için bilgi akışını düzenleyen ve kontrol eden kapılar oluşurlar. Bir hücre girdi kapısı, hücre durumu, unutma kapısı ve çıktı kapısı içerir ve bu kapılar sigmoid veya tanh aktivasyon fonksiyonu kullanır [22]. Bu kapılar ve görevleri aşağıda verilmiştir:

1. Girdi kapıst: Hücre durumunu güncellemek için bir önceki gizli durumu ve şu anki girdiyi alarak sigmoid fonksiyonundan geçirir.

2. Hüсre durumu: Diğer kapıların yardımıla bilgiyi tutmayı veya unutmayı sağlar.

3. Çıktı kapısl: Hücrenin çıktısını oluşturur.

4. Unutma kaptst: Bilginin unutulacak ve tutulacak parçalarına karar verir.

Girdi kapısı, unutma kapısı, çıktı kapısı hücre durumu ve gizli durum değerleri sırasılyla $i_{t}, f_{t}, o_{t}, c_{t}$ ve $h_{t}$ temsil edilmektedir. $x_{t}, t$ zamanındaki girdi vektörü, $\sigma$ sigmoid aktivasyon fonksiyonu ve $\mathrm{W}, \mathrm{b}$ parametre matrisi ve vektörü olmak üzere LSTM hücresi Denklem 2-6'da gösterildiği gibi hesaplanmaktadır [23,24].

$i_{t}=\sigma\left(W_{x i} x_{t}+W_{h i} h_{t-1}+W_{c i} c_{t-1}+b_{i}\right)$

$f_{t}=\sigma\left(W_{x f} x_{t}+W_{h f} h_{t-1}+W_{c f} c_{t-1}+b_{f}\right)$

$c_{t}=f_{t} \odot c_{t-1}+i_{t} \odot \tanh \left(W_{x c} x_{t}+W_{h c} h_{t-1}+b_{c}\right)$

$o_{t}=\sigma\left(W_{x o} x_{t}+W_{h o} h_{t-1}+W_{c o} c_{t}+b_{o}\right)$

$h_{t}=o_{t} \odot \tanh \left(c_{t}\right)$

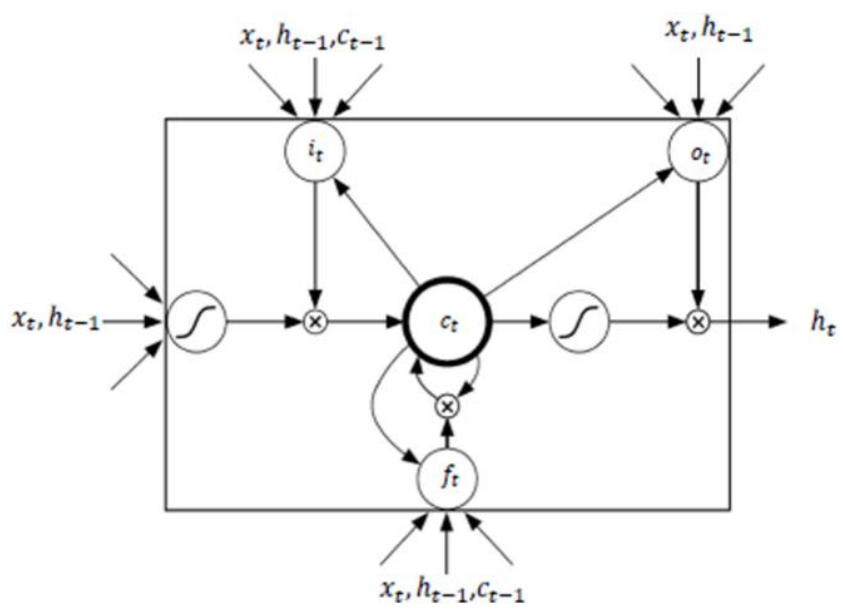

Şekil 4. LSTM Ă̆g Modeli [23]

\section{Deneysel Sonuçlar}

Deneysel çalışmaları gerçekleştirmek için Python programlama dilinin 3.6 .15 versiyonu kullanılmıștır. Kullanılan makinenin teknik özellikleri ise Intel(R) Core (TM) 64-bit, i79750H CPU, 2.60 GHz, 32 GB RAM, Nvidia GeForce RTX 2060.

\subsection{ARIMA Zaman Serisi Modeli Sonuçları}

Çalışmada zaman serisi veri tabanı oluşturulduktan sonra mevsimsel bir trend olup olmadığını gözlemlemek için verilerin ayrıştırma grafikleri çizilmiştir. Günlük vaka sayısının, günlük vefat sayısının ve günlük iyileşen sayısının trend eğilimleri sırasıyla Şekil 5-6-7'de gösterildiği gibidir. 2021 yılı NisanMayıs aylarında hastalığın ciddi bir peak (tepe) yaptığı görülmektedir. Mevsimsel olarak bu aylarda yükseliş beklense de hastalığın verilerini toplamanın üzerinden birkaç sene geçmediğinden bu mevsimsel trendi bu tarih aralıklarına dayandırmak şimdilik modelin doğruluğu için doğru değildir.
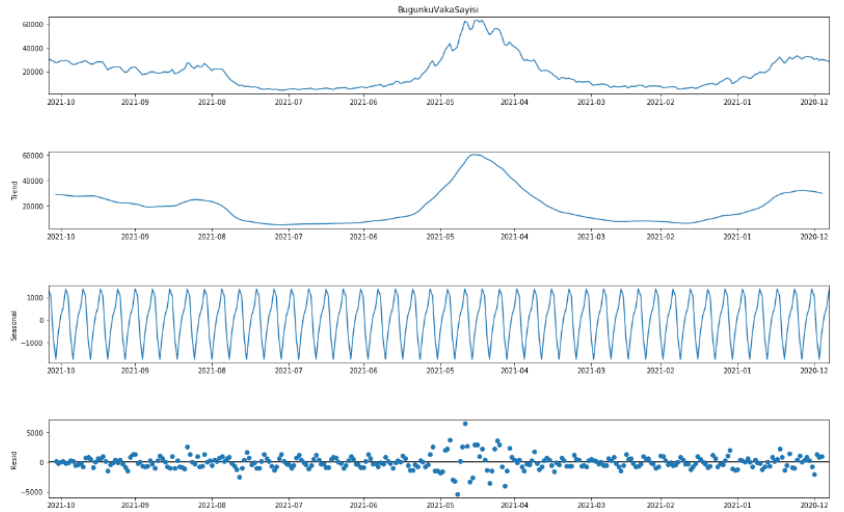

Şekil 5. Günlük Vaka Sayısının Mevsimsel Trend Grafiği
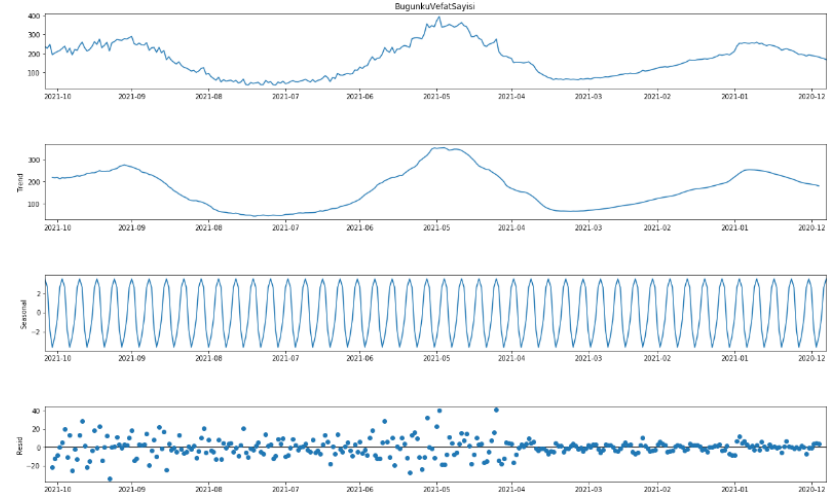

Şekil 6. Günlük Vefat Sayısının Mevsimsel Trend Grafiği
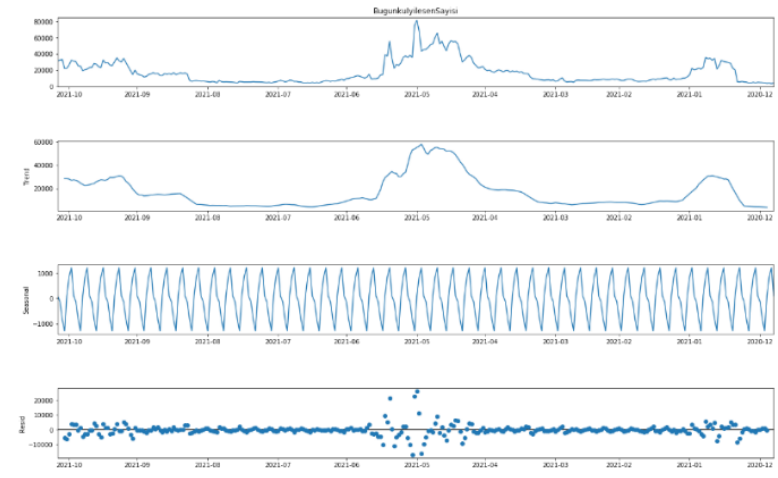

Şekil 7. Günlük Iyileşen Sayısının Mevsimsel Trend Grafiği 
ARIMA modeli daha sonra normallik ve durağanlıktaki varyans için test edilmiştir. Tahmin yapmadan önce gözlem verilerinin durağanlığı kontrol edilmiştir. Ayrıca günlük tahmini yapılan her bir verinin durağanlığını sağlamak için yapılan istatistiksel bir test olan Dickey-Fuller testleri yapılmıştır. Şekil 8 günlük vaka sayısının durağanlığını göstermektedir. Yapılan analiz sonucu günlük vaka sayılarının durağanlık gösterdiği gözlemlenmiştir.

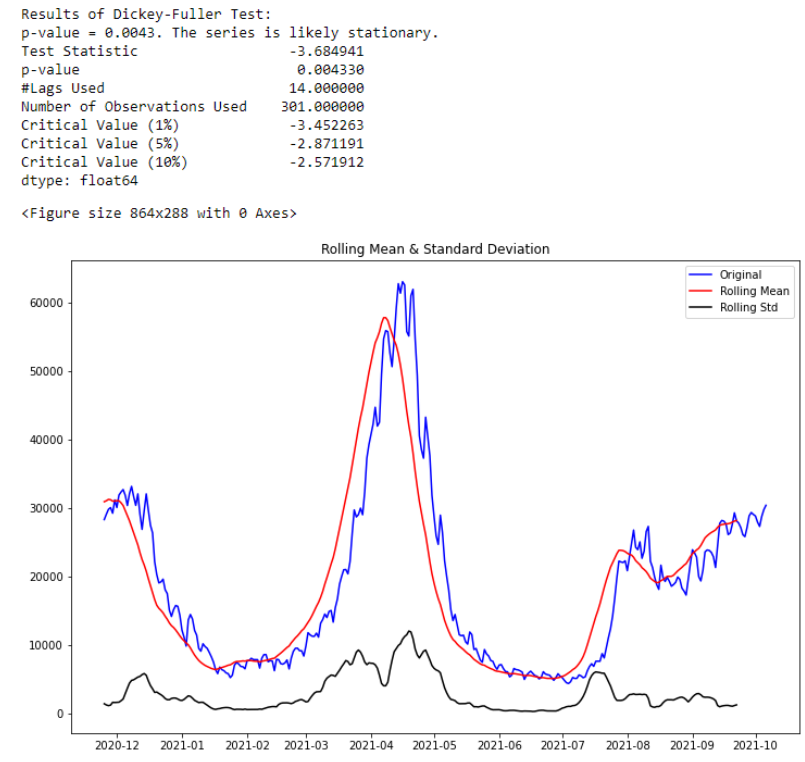

Şekil 8. Günlük Vaka Sayısının Durağanlık ve DF Testi

Şekil 9 günlük vefat sayısının durağanlığını göstermektedir. Yapılan analiz sonucu günlük vefat sayılarının durağanlık gösterdiği gözlemlenmiştir. Şekil 10 günlük iyileşen sayısının durağanlığını göstermektedir. Yapılan analiz sonucu günlük iyileşen sayılarının durağanlık göstermediği gözlemlenmiştir.

ACF grafiği, bir zaman serisi ile gecikmeli değerler arasındaki korelasyon katsayılarının bir çubuk grafiğidir. Basitçe ifade edecek olursak: ACF, belirli bir zaman serisinin şimdiki değerinin geçmiş değerleriyle nasıl ilişkili olduğunu açıklar. ACF grafiğinde, $\mathrm{x}$ ekseni korelasyon katsayısını, y ekseni ise gecikme sayısını ifade eder. PACF, seriler ve kendi gecikmeleri arasındaki kısmi korelasyonu açıklayan kısmi otokorelasyon fonksiyonudur.

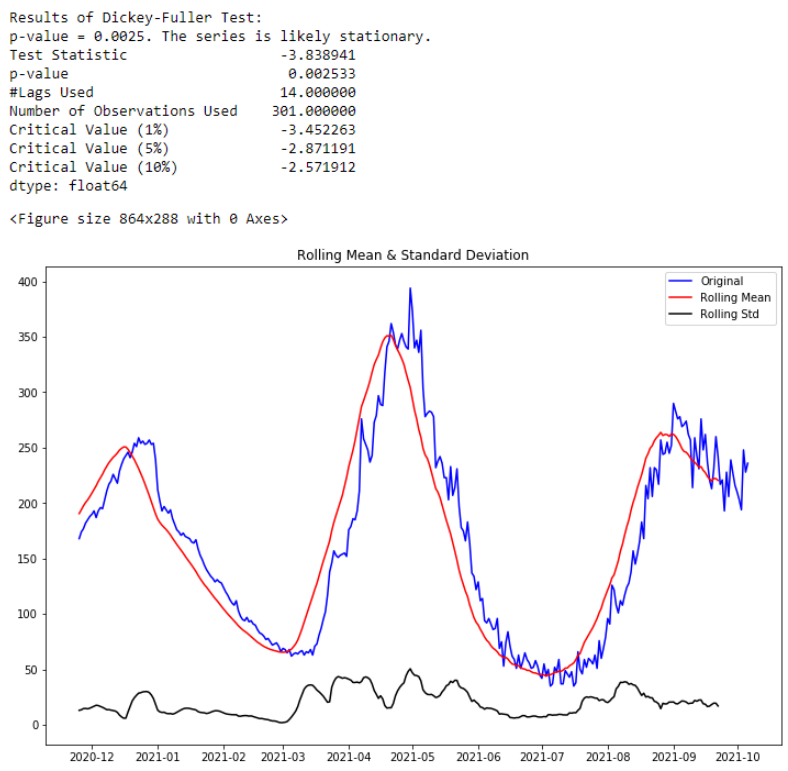

Şekil 9. Günlük Vefat Sayısının Durağanlık ve DF Testi e-ISSN: 2148-2683

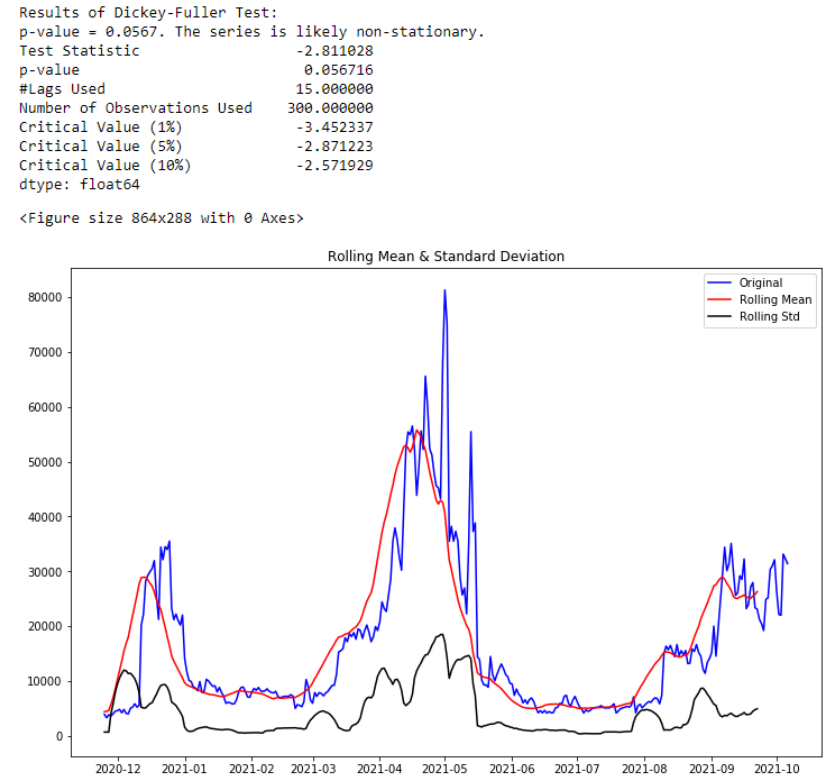

Şekil 10. Günlük İyileşen Sayısının Durağanlık ve DF Testi

ACF ve PACF grafikleri, süreci tanımlamak için birlikte düşünülmelidir. AR süreci için, ACF grafiğinin kademeli olarak azalmasını ve aynı anda PACF'nin $p$ önemli gecikmelerden sonra keskin bir düşüşe sahip olmasını bekliyoruz. Bir MA sürecini tanımlamak için, ACF ve PACF grafiklerinden tam tersini bekleriz, bu şu anlama gelir: ACF belirli bir $q$ gecikme sayısından sonra keskin bir düşüş göstermeli, PACF ise geometrik veya kademeli bir düşüş eğilimi göstermelidir. Öte yandan hem ACF hem de PACF grafikleri kademeli bir azalan model gösteriyorsa, modelleme için ARIMA süreci dikkate alınmalıdır [25]. ARIMA modellerinin başlangıç sayısını bulmak için otokorelasyon fonksiyonu (ACF) grafiği ve kısmi otokorelasyon (PACF) grafiği kullanılmıştır. Günlük vaka sayısının, günlük vefat sayısının ve günlük iyileşen sayısının trend eğilimleri sırasıyla Şekil 11-1213 'te gösterildiği gibidir. Otokorelasyon fonksiyonu, olası tüm gecikmelerde otokorelasyonu verir. Hem ACF hem de PACF grafikleri kademeli bir azalan model gösterdiği için modellemede ARIMA süreci ele alınmıştır.

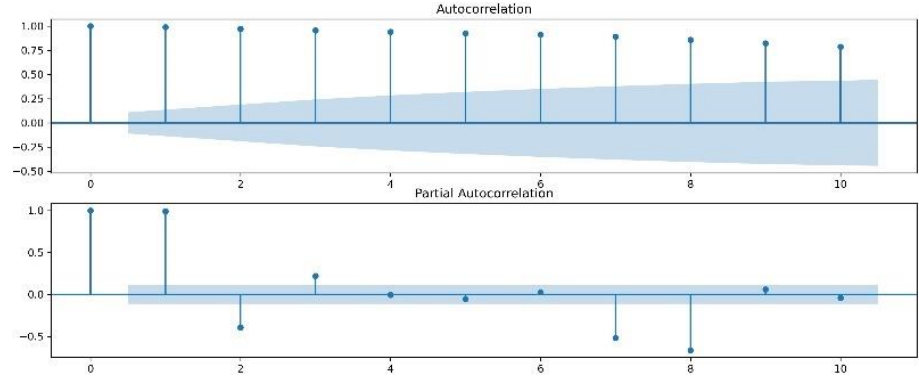

Şekil 11. Günlük Vaka Sayısının Oto\&Kısmı Korelasyon Grafiği

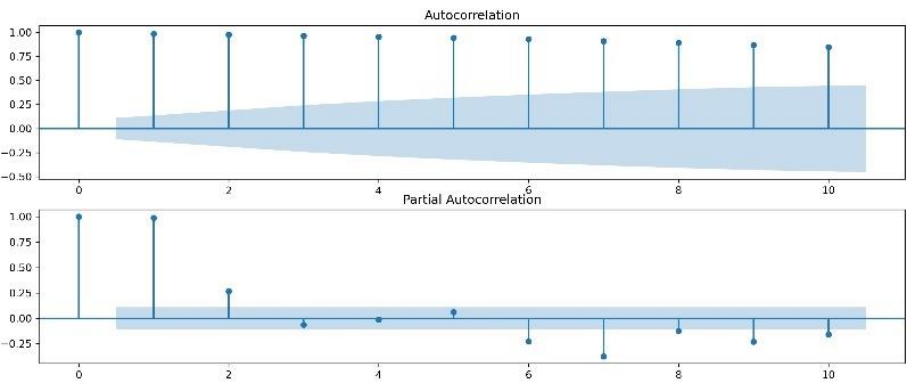

Şekil 12. Günlük Vefat Sayısının Oto\&Kısmı Korelasyon Grafiği 

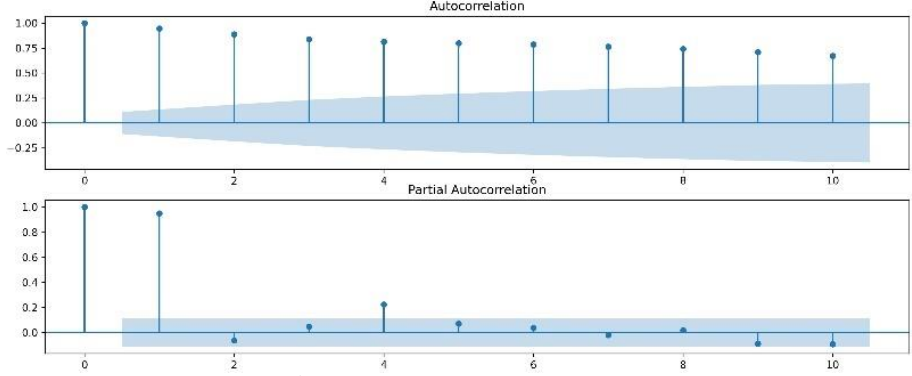

Şekil 13. Günlük Iyileşen Sayısının Oto\&Kısmı Korelasyon Grafiği

ARIMA zaman serisi modelini kullanarak Türkiye'deki COVID-19 bulaşısının tahmin edilen 15 günlük vaka sayısında, vefat sayısında ve iyileşen sayısında azalmaya yönelik bir regresyon eğrisi Şekil 14-15-16'da gösterildiği gibi elde edilmiştir. Grafikler üzerinde var olan veri, bilinen verinin tahmini ve bilinmeyen 15 günlük tahmin gösterilmiştir. Bilinen verinin tahminine bakıldığında yüksek doğruluk yüzdesiyle grafiğin çizdirildiği gözlemlenmektedir.

Tahmin modelinin doğruluğunu göstermek için performans değerlendirme metriklerinden Denklem 7'de formülü verilmiş olan ortalama mutlak yüzde hatası (mean absolute percentage error-MAPE) kullanılmıştır. MAPE, gerçek ve tahmin edilen değerler arasındaki farkı hesaplar. MAPE yüzdesi ne kadar düşükse modelin doğruluğu o kadar yüksektir. Burada $G$ gerçek değeri, $T$ tahmin edilen değeri ve $n$ ise tahmin edilen toplam veri sayısını temsil etmektedir.

$$
M A P E=\frac{1}{n} \sum_{t=1}^{n}\left|\frac{G_{t}-T_{t}}{G_{t}}\right|
$$

Tablo 1'de gösterildiği gibi, tahmini yapılan gelecek 15 günlük sağlık bakanlığının ilan ettiği verilerle karşılaştırıldığında, ARIMA modelinde Türkiye'deki COVID-19 bulaşısının gelecek 15 günlük vaka sayısı $\% 5,71$, vefat sayısı $\% 11,87$ ve iyileşen sayıs $\% 9,87$ hata oranları ile elde edilmiştir.

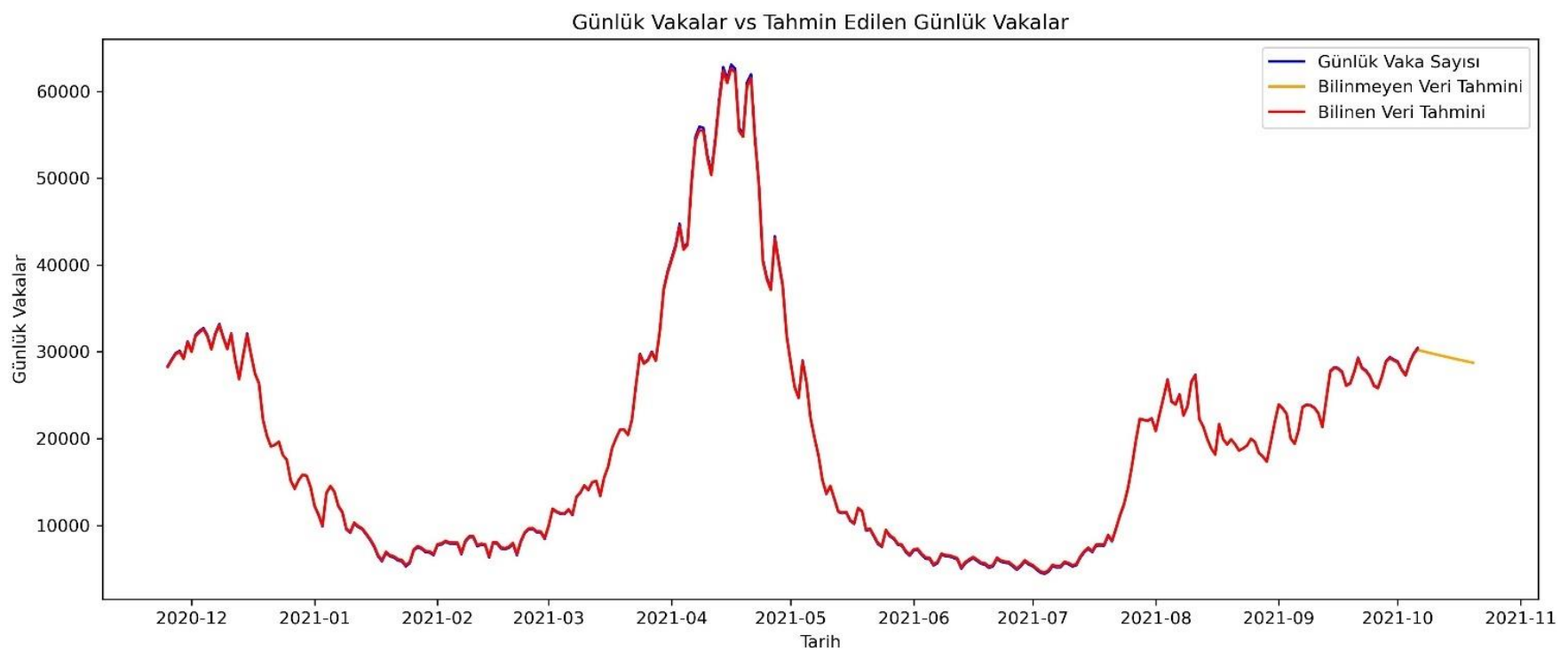

Şekil 14. ARIMA Modelinde Günlük Vaka Sayıları vs Tahmin Edilen Günlük Vaka Sayıları

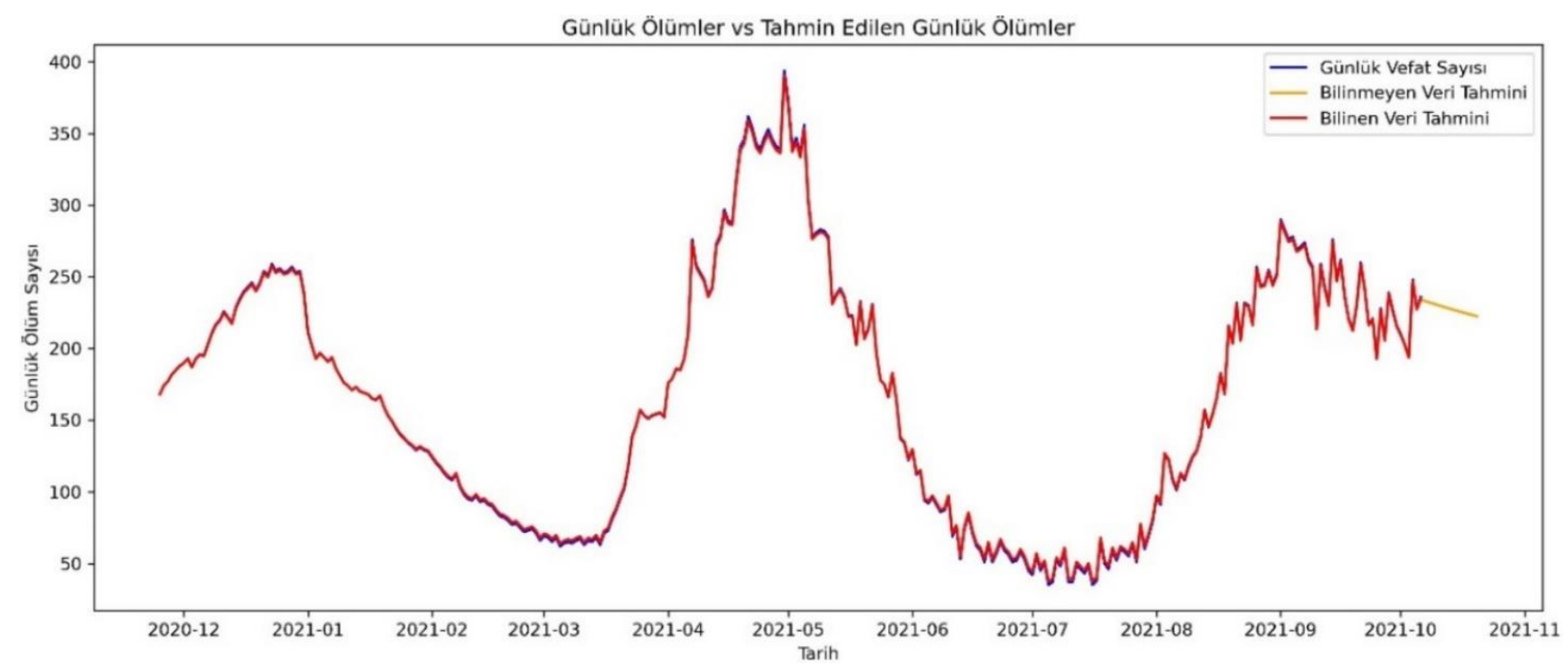

Şekil 15. ARIMA Modelinde Günlük Vefat Saylları vs Tahmin Edilen Günlük Vefat Sayıları 
Günlük İyileşmeler vs Tahmin Edilen Günlük İyileşmeler

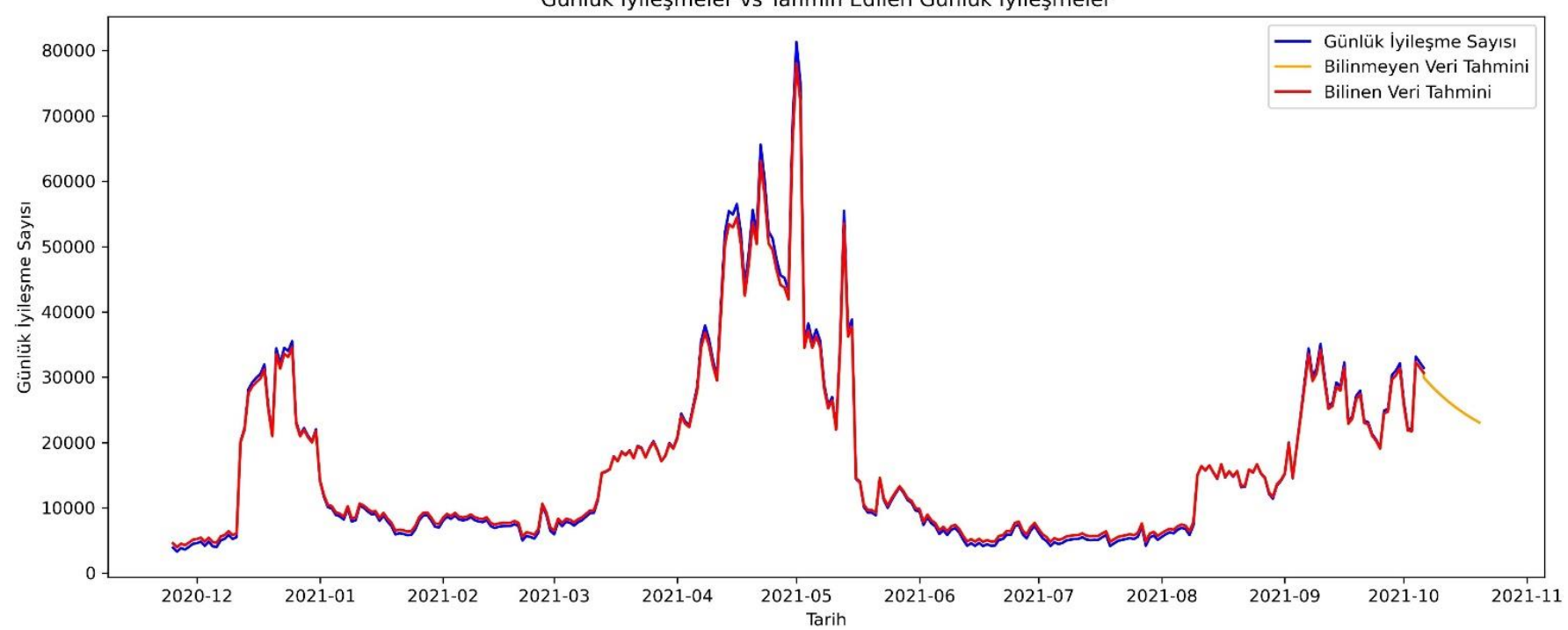

Şekil 16. ARIMA Modelinde Günlük Iyileşen Sayıları vs Tahmin Edilen Günlük Iyileşen Sayıları

Tablo 1. ARIMA Modelinde Tahmin Edilen COVID-19 Bulaşının MAPE Sonuçları

\begin{tabular}{|c|c|c|c|c|c|c|c|c|c|}
\hline \multirow[b]{2}{*}{ Tarih } & \multicolumn{3}{|c|}{ Günlük Vaka } & \multicolumn{3}{|c|}{ Günlük Vefat } & \multicolumn{3}{|c|}{ Günlük İyileșen } \\
\hline & $\begin{array}{c}\text { Gerçek Vaka } \\
\text { Sayısı }\end{array}$ & $\begin{array}{c}\text { Tahmin Edilen } \\
\text { Vaka Sayısı }\end{array}$ & $\begin{array}{c}\text { Hata } \\
\text { Yüzdesi }\end{array}$ & $\begin{array}{l}\text { Gerçek Vefat } \\
\text { Sayısı }\end{array}$ & $\begin{array}{c}\text { Tahmin Edilen } \\
\text { Vefat Sayısı }\end{array}$ & $\begin{array}{c}\text { Hata } \\
\text { Yüzdesi }\end{array}$ & $\begin{array}{c}\text { Gerçek İyileşen } \\
\text { Sayısı }\end{array}$ & $\begin{array}{l}\text { Tahmin Edilen } \\
\text { İyileşen Sayısı }\end{array}$ & $\begin{array}{c}\text { Hata } \\
\text { Yüzdesi }\end{array}$ \\
\hline 7 Ekim 2021 & 30019 & 30208 & $\% 0,63$ & 217 & 234 & $\% 7,89$ & 32240 & 29946 & $\% 7,11$ \\
\hline 9 Ekim 2021 & 28645 & 29984 & $\% 4,67$ & 206 & 232 & $\% 12,76$ & 24217 & 28626 & $\% 18,21$ \\
\hline 10 Ekim 2021 & 28370 & 29873 & $\% 5,30$ & 196 & 231 & $\% 18,06$ & 25772 & 28017 & $\% 8,71$ \\
\hline 13 Ekim 2021 & 31248 & 29549 & $\% 5,43$ & 236 & 228 & $\% 3,03$ & 30331 & 26370 & $\% 13,05$ \\
\hline 14 Ekim 2021 & 30709 & 29443 & $\% 4,12$ & 203 & 228 & $\% 12,31$ & 26461 & 25877 & $\% 2,20$ \\
\hline 15 Ekim 2021 & 30694 & 29338 & $\% 4,41$ & 181 & 227 & $\% 25,51$ & 25513 & 25408 & $\% 0,41$ \\
\hline 16 Ekim 2021 & 28537 & 29234 & $\% 2,44$ & 212 & 226 & $\% 6,78$ & 25611 & 24964 & $\% 2,52$ \\
\hline 20 Ekim 2021 & 29760 & 28829 & $\% 3,12$ & 214 & 223 & $\% 4,33$ & 28803 & 23405 & $\% 18,74$ \\
\hline \multirow[t]{2}{*}{21 Ekim 2021} & 28465 & 28730 & $\% 0,93$ & 198 & 222 & $\% 12,39$ & 29160 & 23064 & $\% 20,90$ \\
\hline & & & $\begin{array}{l}\text { MAPE } \\
\% 4,95\end{array}$ & & & $\begin{array}{l}\text { MAPE } \\
\% 11,87\end{array}$ & & & $\begin{array}{l}\text { MAPE } \\
\% 9,87\end{array}$ \\
\hline
\end{tabular}

\subsection{LSTM Sinir Ăğ Sonuçları}

Tahminleme için tek değişkenli zaman serisi modeli geliştirilmiştir. Tahmin modeli 3 LSTM katmanı içermektedir. Aktivasyon fonksiyonu olarak tanh seçilmiştir. Her bir katmandaki nöron sayısı hiperparametre optimizasyonu kullanılarak elde edilmiştir ve optimizer olarak adam optimizer kullanılmıştır ve öğrenme katsayısı $\beta=0.01$ seçilmiştir. Geliştirilen model tensorflow keras ile gerçekleştirilmiştir. Veri seti $80 \%$ eğitim, 20\% test olarak ayrılmıştır. Eğitim verisi 14 günlük zaman dilimi olarak biçimlendirilmiştir. Model 100 epoch ve 4 batch boyutu kullanılarak eğitilmiştir. Model eğitim verisi ile doğrulanmış, test verisi ile test edilmiştir. Ortalama mutlak hata yüzdesi (MAPE) ölçeği ile model başarısı ölçülmüştür. Model başarısı değerleri Tablo 2'de ARIMA ve LSTM modellerindeki doğrulama ve test MAPE değerleri gösterilmiştir. Doğrulama MAPE değerleri, bilinen verinin tahmin edilmesi olup yüzde kaç hata ile doğru bilindiğini göstermektedir. ARIMA modelinde test MAPE değerleri, bilinen verinin son \%20'lik kısmının test verisi kabul edilip tahmin edilmesidir. Burada yüzde kaç hata ile doğru bilindiğini göstermektedir. LSTM modelinde test MAPE değerleri, \%20'lik test verisinin yüzde kaç hata ile doğru tahminlendiğini göstermektedir. Tablo 2'de gösterildiği gibi, günlük vaka, vefat ve iyileşen sayısında doğrulama ve test MAPE değerlerinde ARIMA modelinde daha az hata ile modelin tahminlendiği gözlemlenmiştir. LSTM ağ modelinde bir sonraki gün tahmini gerçekleştirildiğinden hata yüzdelerinde daha yüksek oranlar elde edildiği anlaşılmaktadır. 
LSTM ağ modeli kullanılarak vaka, vefat ve iyileşen sayısının gelecek 15 günlük tahmini Şekil 17-18-19'da gösterildiği gibidir. LSTM ağı kullanılarak Türkiye'deki COVID19 bulaşı seyri deneysel sonuçları ve gelecek 15 günlük tahmin grafiklerine bakıldığında günlük vaka ve günlük vefat sayısında azalma, günlük iyileşen sayısında ise artma seyri gösterdiği gözlemlenmiştir.

Tablo 3'te gösterildiği gibi, tahmini yapılan gelecek 15 günlük sağlık bakanlığının ilan ettiği verilerle karşılaştırıldığında, LSTM ağ modelinde Türkiye'deki COVID-19 bulaşısının gelecek 15 günlük vaka sayısı $\% 14,85$, vefat sayıs $\% 8,60$ ve iyileşen sayıs $\% 20,98$ hata oranları ile elde edilmiştir.

Tablo 1 ve Tablo 3'te gösterildiği gibi, Türkiye'de bulaşı seyrinde gelecek tahmini ARIMA ve LSTM modelleriyle gerçekleştirildiğinde, bilinmeyen verilerin tahmininde ARIMA modelinin daha yüksek doğrukla tahmin ettiğgi gözlemlenmektedir. Günlük vaka sayısında LSTM ağında elde edilen hata yüzdesi \%61,54 oranında, günlük iyileşen sayısında \%52,95 oranında azalma ARIMA modelinde elde edilmiştir.
Günlük vefat saısında ise ARIMA modelinde elde edilen hata yüzdesi $\% 27,54$ oranında azalma LSTM ağ modelinde elde edilmiştir.

Tablo 2. Doğrulama ve Test MAPE Yüzdeleri

\begin{tabular}{|c|c|c|c|c|}
\hline & \multicolumn{2}{|c|}{ ARIMA } & \multicolumn{2}{c|}{ LSTM } \\
\hline & $\begin{array}{c}\text { Doğrulama } \\
\text { MAPE }\end{array}$ & $\begin{array}{c}\text { Test } \\
\text { MAPE }\end{array}$ & $\begin{array}{c}\text { Doğrulama } \\
\text { MAPE }\end{array}$ & $\begin{array}{c}\text { Test } \\
\text { MAPE }\end{array}$ \\
\hline $\begin{array}{c}\text { Günlük } \\
\text { Vaka }\end{array}$ & $\% 0,91$ & $\% 0,19$ & $\% 9,10$ & $\% 5,61$ \\
\hline $\begin{array}{c}\text { Günlük } \\
\text { Vefat }\end{array}$ & $\% 1,21$ & $\% 0,43$ & $\% 6,76$ & $\% 6,64$ \\
\hline $\begin{array}{c}\text { Günlük } \\
\text { İyileșen }\end{array}$ & $\% 5,41$ & $\% 2,01$ & $\% 25,21$ & $\% 15,02$ \\
\hline
\end{tabular}

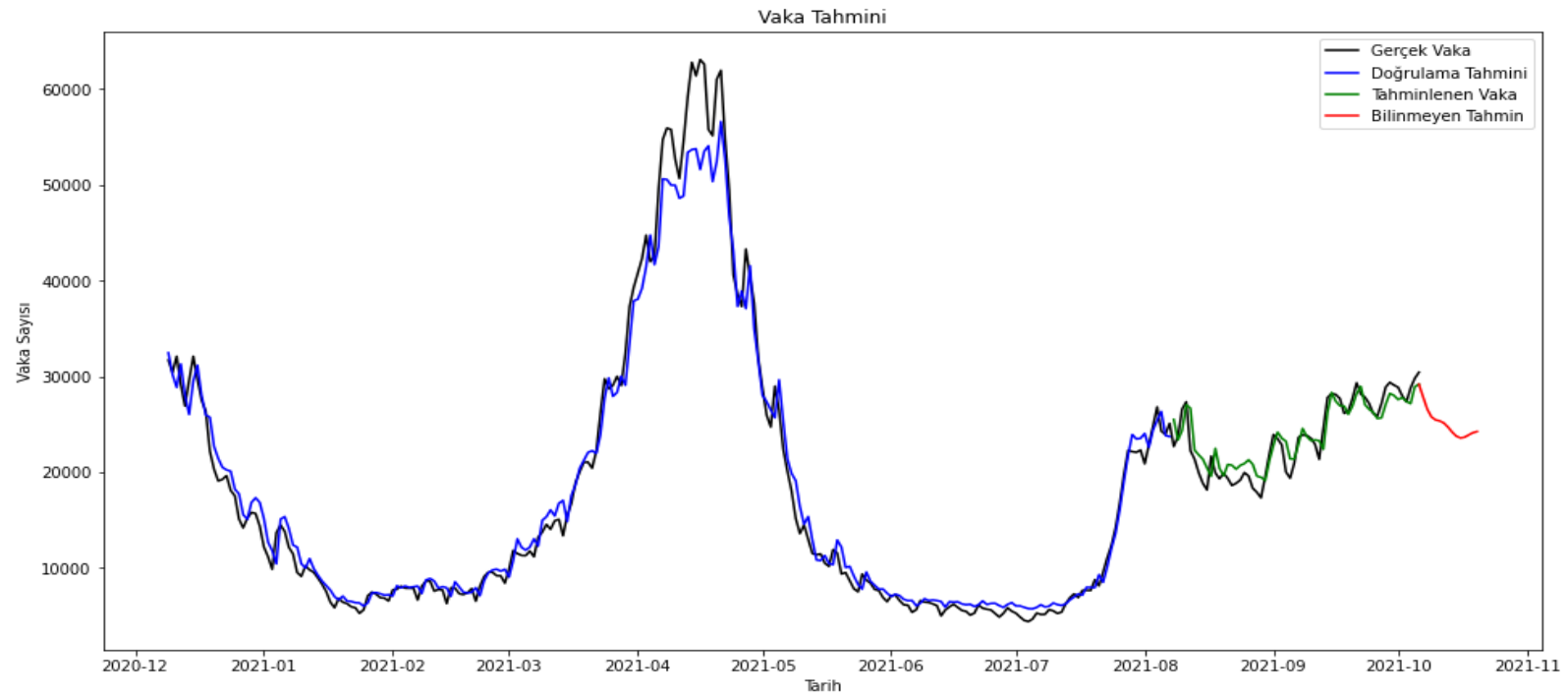

Şekil 17. LSTM Ağında Günlük Vaka Sayıları vs Tahmin Edilen Günlük Vaka Sayıları

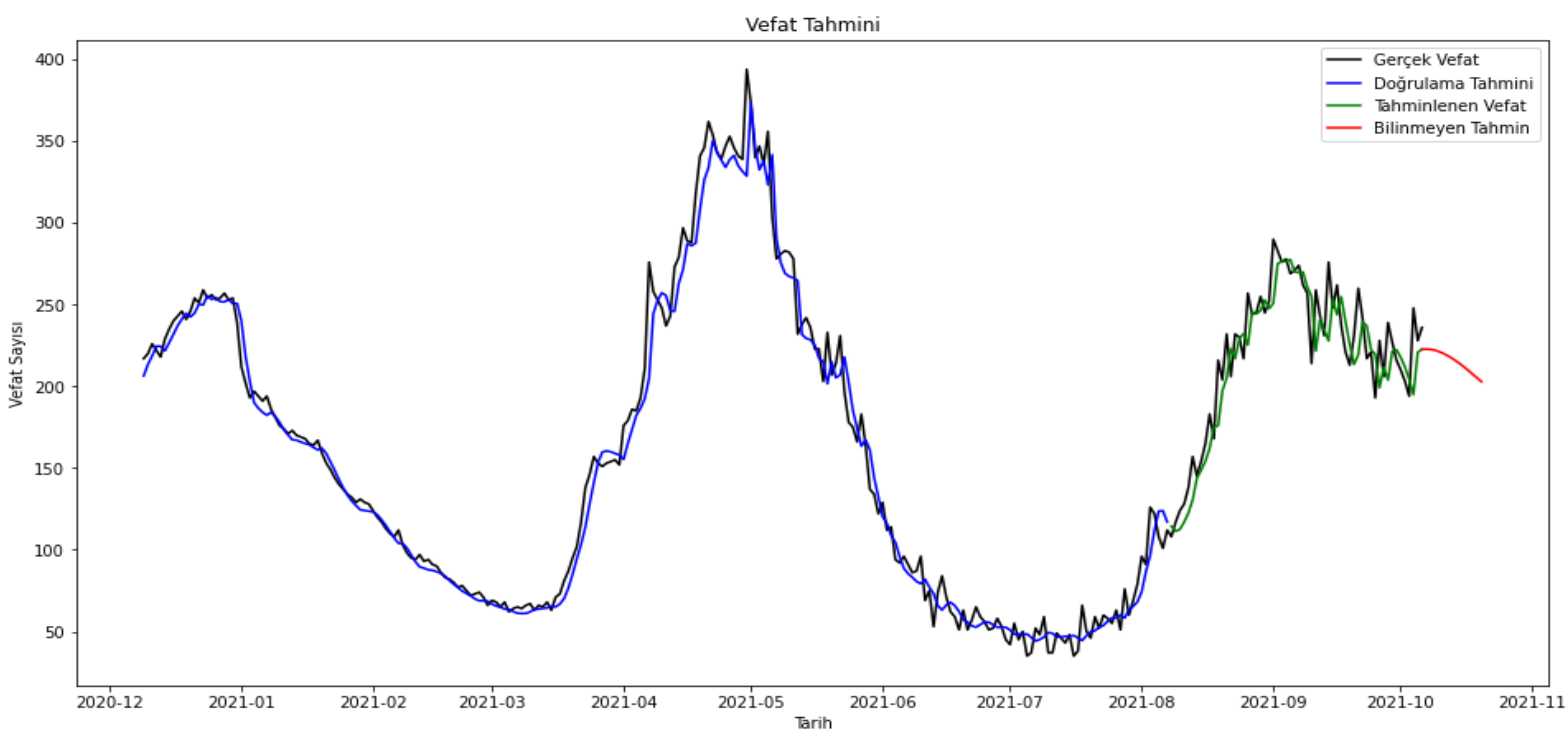

Şekil 18. LSTM Ağında Günlük Vefat Saylları vs Tahmin Edilen Günlük Vefat Sayıları 


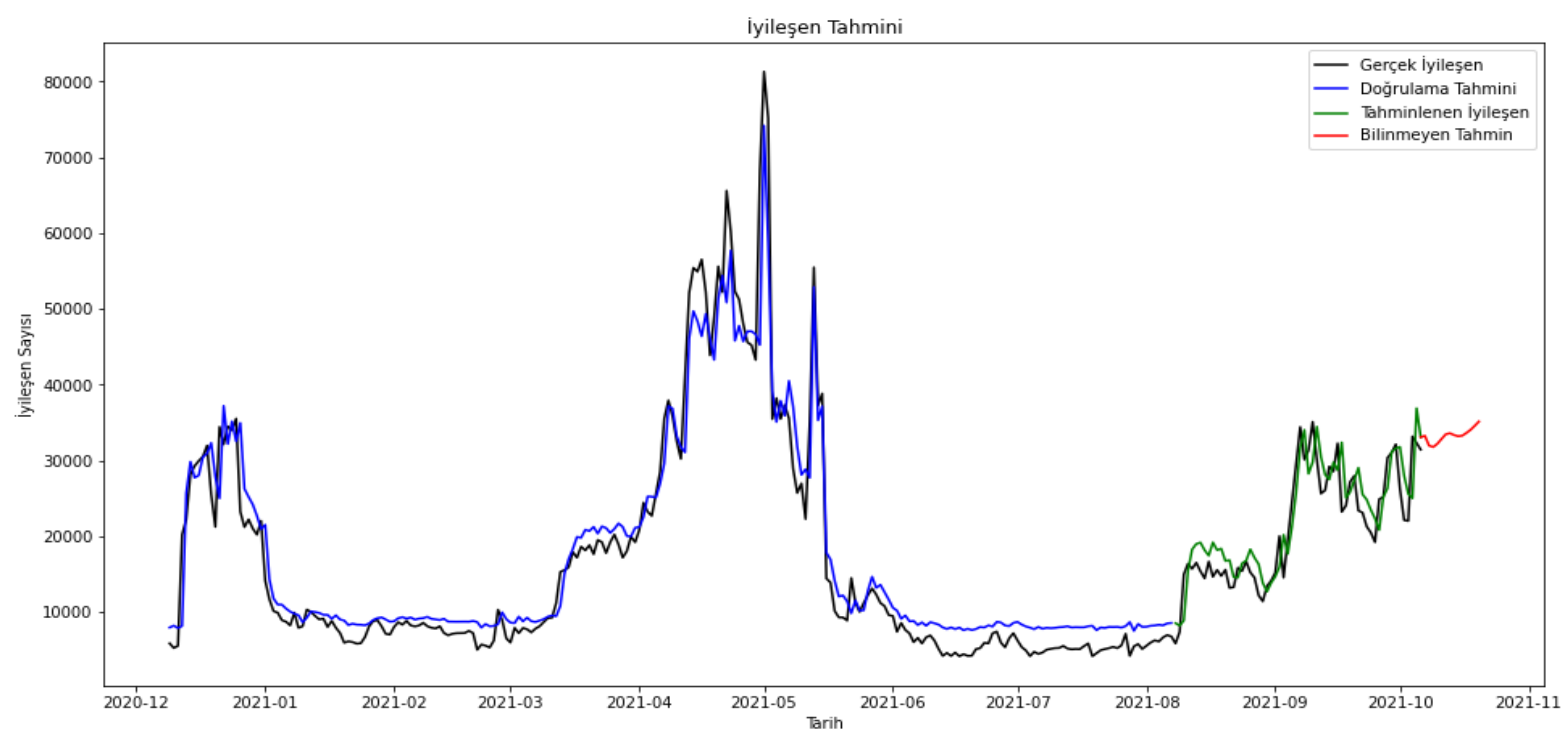

Şekil 19. LSTM Ağında Günlük Iyileşen Sayıları vs Tahmin Edilen Günlük Iyileşen Sayıları

Tablo 3. LSTM Ă̆ında Tahmin Edilen COVID-19 Bulaşının MAPE Sonuçları

\begin{tabular}{|c|c|c|c|c|c|c|c|c|c|}
\hline \multirow[b]{2}{*}{ Tarih } & \multicolumn{3}{|c|}{ Günlük Vaka } & \multicolumn{3}{|c|}{ Günlük Vefat } & \multicolumn{3}{|c|}{ Günlük İyileşen } \\
\hline & $\begin{array}{c}\text { Gerçek Vaka } \\
\text { Sayısı } \\
\end{array}$ & $\begin{array}{c}\text { Tahmin Edilen } \\
\text { Vaka Sayısı } \\
\end{array}$ & $\begin{array}{c}\text { Hata } \\
\text { Yüzdesi }\end{array}$ & $\begin{array}{c}\text { Gerçek Vefat } \\
\text { Sayısı } \\
\end{array}$ & $\begin{array}{c}\text { Tahmin Edilen } \\
\text { Vefat Sayısı } \\
\end{array}$ & $\begin{array}{c}\text { Hata } \\
\text { Yüzdesi }\end{array}$ & $\begin{array}{c}\text { Gerçek } \\
\text { İyileşen Sayısı }\end{array}$ & $\begin{array}{l}\text { Tahmin Edilen } \\
\text { İyileșen Sayısı }\end{array}$ & $\begin{array}{c}\text { Hata } \\
\text { Yüzdesi }\end{array}$ \\
\hline 7 Ekim 2021 & 30019 & 29185 & $\% 2,77$ & 217 & 222 & $\% 7,89$ & 32240 & 33056 & $\% 7,11$ \\
\hline 8 Ekim 2021 & 30201 & 27880 & $\% 7,68$ & 188 & 222 & $\% 24,04$ & 28167 & 33239 & $\% 3,91$ \\
\hline 9 Ekim 2021 & 28645 & 26605 & $\% 7,12$ & 206 & 222 & $\% 12,76$ & 24217 & 31937 & $\% 18,21$ \\
\hline 10 Ekim 2021 & 28370 & 25792 & $\% 9,08$ & 196 & 222 & $\% 18,06$ & 25772 & 31750 & $\% 8,71$ \\
\hline 11 Ekim 2021 & 30563 & 25473 & $\% 16,65$ & 188 & 221 & $\% 22,62$ & 33861 & 32192 & $\% 18,96$ \\
\hline 12 Ekim 2021 & 33860 & 25361 & $\% 25,10$ & 237 & 220 & $\% 3,08$ & 30110 & 32818 & $\% 10,69$ \\
\hline 13 Ekim 2021 & 31248 & 25150 & $\% 19,51$ & 236 & 218 & $\% 3,03$ & 30331 & 33434 & $\% 13,05$ \\
\hline 14 Ekim 2021 & 30709 & 24725 & $\% 19,48$ & 203 & 217 & $\% 12,31$ & 26461 & 33579 & $\% 2,20$ \\
\hline 15 Ekim 2021 & 30694 & 24199 & $\% 21,16$ & 181 & 215 & $\% 25,51$ & 25513 & 33339 & $\% 0,41$ \\
\hline 16 Ekim 2021 & 28537 & 23772 & $\% 16,69$ & 212 & 213 & $\% 6,78$ & 25611 & 33182 & $\% 2,52$ \\
\hline 17 Ekim 2021 & 24114 & 23586 & $\% 2,18$ & 186 & 211 & $\% 21,28$ & 24403 & 33259 & $\% 0,57$ \\
\hline 18 Ekim 2021 & 29240 & 23663 & $\% 19,07$ & 214 & 209 & $\% 5,04$ & 26539 & 33620 & $\% 9,02$ \\
\hline 19 Ekim 2021 & 30862 & 23904 & $\% 22,54$ & 223 & 207 & $\% 0,46$ & 27352 & 34034 & $\% 13,11$ \\
\hline 20 Ekim 2021 & 29760 & 24134 & $\% 18,90$ & 214 & 205 & $\% 4,33$ & 28803 & 34568 & $\% 18,74$ \\
\hline 21 Ekim 2021 & 28465 & 24254 & $\% 14,79$ & 198 & 202 & $\% 12,39$ & 29160 & 35125 & $\% 20,91$ \\
\hline & & & $\begin{array}{l}\text { MAPE } \\
\% 14,85\end{array}$ & & & $\begin{array}{l}\text { MAPE } \\
\% 8,60\end{array}$ & & & $\begin{array}{l}\text { MAPE } \\
\% 20,98\end{array}$ \\
\hline
\end{tabular}

\section{Sonuçlar ve Gelecek Çalışmalar}

COVID-19 küresel salgını tüm dünyada olduğu gibi ülkemizde de birçok alanda olumsuz etkilere neden olmuştur. Alınan tedbirlere rağmen vakaların hayatı olumsuz etkilediği kaçınılmaz bir gerçektir. COVID-19 bulaşısının seyrinin tahmin edilmesi alınacak tedbirler için hayati önem taşımaktadır. $\mathrm{Bu}$ çalışmada, Türkiye'deki COVID-19 bulaşısının günlük vaka sayısının, günlük vefat sayısının ve günlük iyileşen sayısının gelecek 15 günlük tahmini için ARIMA zaman serisi modeli ve LSTM sinir ağ1 modeli kullanılmıştır. Yapılan deneysel çalışmalar sonucu ARIMA ve LSTM modellerinde bulaşı seyrinin düşme eğiliminde olduğu gözlemlenmiştir.
ARIMA modelinde MAPE tahmin hatası vaka sayıları için \%4,95, vefat sayıları için \%11,87 ve iyileşen sayıları için $\% 9,87$ olarak elde edilirken, LSTM modelinde MAPE tahmin hatası vaka sayıları için \%14,85, vefat sayıları için \%8,60 ve iyileşen sayıları için \%20,98 olarak elde edilmiştir. Modellerin doğruluğunu test etmek için bilinen ve bilinmeyen verilerin tahmini yapılarak tahmini yapılan verilerin hata yüzdeleri karşılaştırılmıştır. Türkiye'de COVID-19 bulaşı seyrinin gelecek 15 günlük tahmini için yapılan deneysel çalışmalar sonucu günlük vaka sayılarında ve günlük vefat sayılarında ARIMA modeliyle daha yüksek doğrulukta tahminleme yapıldığı, günlük iyileşen sayılarında ise LSTM modeliyle daha yüksek doğrulukta tahminleme yapıldığ́ gözlemlenmiştir. Yapılan tüm deneysel çalışmalar sonucu, ARIMA ve LSTM modellerinde günlük vaka ve vefat 
sayılarında azalma seyri gözlemlenmiştir. Günlük iyileşme sayılarında ise ARIMA modelinde azalma gözlemlenirken LSTM ağ modelinde artış gözlemlenmiştir.

Gelecekte yapmayı planladığımız çalışmalar ise şu şekildedir;

$\rightarrow$ Vakaların, vefatların ve iyileşmelerin birbiriyle olan ilişkileri incelenebilir.

$\rightarrow$ Başka bir zaman serisi modeli olan SARIMAX modeliyle de karşılaştırma yapılabilir.

$\rightarrow$ Aşılama sürecinin salgının seyrine olan etkisi zaman serisi modelleriyle incelenebilir.

\section{Kaynakça}

1. Chawla, S., Mittal, M., Chawla, M., \& Goyal, L. M. (2020). Corona virus-SARS-CoV-2: an insight to another way of natural disaster. EAI Endorsed Transactions on Pervasive Health and Technology, 6(22).

2. Wang, L. L., \& Lo, K. (2021). Text mining approaches for dealing with the rapidly expanding literature on COVID19. Briefings in Bioinformatics, 22(2), 781-799.

3. Er, B., Emeç, M., \& Özcanhan, M. H. (2020). Analysıs Of Covid-19 Data Using Arima Time Series Model.

4. Zeroual, A., Harrou, F., Dairi, A., \& Sun, Y. (2020). Deep learning methods for forecasting COVID-19 time-Series data: A Comparative study. Chaos, Solitons \& Fractals, 140, 110121.

5. Barman, A. (2020). Time series analysis and forecasting of covid-19 cases using LSTM and ARIMA models. arXiv preprint arXiv:2006.13852.

6. Anne, R. (2020). ARIMA modelling of predicting COVID19 infections. medRxiv.

7. Ding, G., Li, X., Shen, Y., \& Fan, J. (2020). Brief Analysis of the ARIMA model on the COVID-19 in Italy. medRxiv.

8. Sahai, A. K., Rath, N., Sood, V., \& Singh, M. P. (2020). ARIMA modelling \& forecasting of COVID-19 in top five affected countries. Diabetes \& Metabolic Syndrome: Clinical Research \& Reviews, 14(5), 1419-1427.

9. Maleki, M., Mahmoudi, M. R., Heydari, M. H., \& Pho, K. H. (2020). Modeling and forecasting the spread and death rate of coronavirus (COVID-19) in the world using time series models. Chaos, Solitons \& Fractals, 140, 110151.

10. Papastefanopoulos, V., Linardatos, P., \& Kotsiantis, S. (2020). COVID-19: a comparison of time series methods to forecast percentage of active cases per population. Applied sciences, 10(11), 3880.

11. Chimmula, V. K. R., \& Zhang, L. (2020). Time series forecasting of COVID-19 transmission in Canada using LSTM networks. Chaos, Solitons \& Fractals, 135, 109864.

12. Maleki, M., Mahmoudi, M. R., Wraith, D., \& Pho, K. H. (2020). Time series modelling to forecast the confirmed and recovered cases of COVID-19. Travel medicine and infectious disease, 37, 101742.

13. Akay, S., \& Akay, H. (2021). Time series model for forecasting the number of COVID-19 cases in Turkey. Turkish Journal of Public Health, 140-145.

14. ANKARALI, H. (2020). Türkiye'de COVID-19 Salgın Sürecinde İhtiyaç Duyulacak Yoğun Bakım Yatak ve Solunum Cihazı Sayılarının Direkt Tahmini. Anatolian Clinic the Journal of Medical Sciences, 25(Special Issue on COVID 19), 59-62.
15. Koçak, M. (2020). A comparison of time-series models in predicting COVID-19 cases. Türkiye Klinikleri Biyoistatistik, 12(1), 89-96.

16. Ergül, B., Altın Yavuz, A., Gündoğan Aşık, E., \& Kalay, B. (2020). Dünya'da ve Türkiye'de nisan ayı itibariyle Covid-19 salgın verilerinin istatistiksel değerlendirilmesi. Anadolu Kliniği Tıp Bilimleri Dergisi, 25(1), 130-141.

17. Bayar, M., \& VARIŞLI, N. (2020). Covid-19 Pandemisinin Türkiye'de Tüketici Kredileri Hacmi Üzerindeki Etkisi: 2013-2020 Dönemi Zaman Serisi Analizi. Anadolu Üniversitesi İktisadi ve İdari Bilimler Fakültesi Dergisi, 21(3), 85-99.

18. Demir, İ. (2020). COVID-19 Salgınının Seyri ve Türkiye Ekonomisi: Bir Sekteli Zaman Serisi Analizi (Szsa) Denemesi. Disiplinlerarası Politika Vizyonu ve Stratejiler Dergisi.

19. Karasoy, O., \& EREN DOĞU, Z. F. (2020). COVID19Takip: Türkiye'de COVID-19 Salgınının Gerçek Zamanlı İzlenmesi için Web Arayüzü. Turkiye Klinikleri Journal of Biostatistics, 12(1).

20. Er, B., Emeç, M., \& Özcanhan, M. H. ANALYSIS OF COVID-19 DATA USING ARIMA TIME SERIES MODEL.

21. Ergül, B., Altın Yavuz, A., Gündoğan Aşık, E., \& Kalay, B. (2020). Dünya'da ve Türkiye'de nisan ayı itibariyle Covid-19 salgın verilerinin istatistiksel değerlendirilmesi. Anadolu Kliniği Tıp Bilimleri Dergisi, 25(1), 130-141.

22. Selvin, S., Vinayakumar, R., Gopalakrishnan, E. A., Menon, V. K., \& Soman, K. P. (2017, September). Stock price prediction using LSTM, RNN and CNN-sliding window model. In 2017 international conference on advances in computing, communications and informatics (icacci) (pp. 1643-1647). IEEE.

23. Graves, A. (2013). Generating sequences with recurrent neural networks. arXiv preprint arXiv:1308.0850.

24. Karevan, Z., \& Suykens, J. A. (2020). Transductive LSTM for time-series prediction: An application to weather forecasting. Neural Networks, 125, 1-9.

25. Ulyah, S. M., \& Mardianto, M. F. F. (2019, December). Comparing the Performance of Seasonal ARIMAX Model and Nonparametric Regression Model in Predicting Claim Reserve of Education Insurance. In Journal of Physics: Conference Series (Vol. 1397, No. 1, p. 012074). IOP Publishing. 